\title{
Epididymis Response Partly Compensates for Spermatozoa Oxidative Defects in SnGPx4 and GPx5 Double Mutant Mice
}

\author{
Anaïs Noblanc ${ }^{1}$, Manon Peltier ${ }^{2}$, Christelle Damon-Soubeyrand ${ }^{1}$, Nicolas Kerchkove ${ }^{1}$, \\ Eléonore Chabory ${ }^{3}$, Patrick Vernet ${ }^{1}$, Fabrice Saez ${ }^{1}$, Rémi Cadet ${ }^{1}$, Laurent Janny ${ }^{1,4}$, Hanae Pons-Rejraji ${ }^{1,4}$, \\ Marcus Conrad $^{5}$, Joël R. Drevet ${ }^{1 *}$, Ayhan Kocer ${ }^{1}$
}

1 Genetics Reproduction \& Development laboratory, CNRS UMR 6293 - INSERM U1 103 - Clermont Université, Aubière, France, 2 Institut Curie, Paris, France, 3 Laboratoire d'Assistance Médicale à la Procréation, Département gynécologie-obstétrique, Hôpital Porte Madeleine, Orléans, France, $\mathbf{4}$ CHU Estaing, Assistance Médicale à la Procréation, Clermont-Ferrand, France, $\mathbf{5}$ German Center for Neurodegenerative Diseases, Munich, Germany and Helmholtz Zentrum München, German Research Center for Environmental Health, Institute of Developmental Genetics, Neuherberg, Germany

\begin{abstract}
We report here that spermatozoa of mice lacking both the sperm nucleaus glutathione peroxidase 4 (snGPx4) and the epididymal glutathione peroxidase 5 (GPx5) activities display sperm nucleus structural abnormalities including delayed and defective nuclear compaction, nuclear instability and DNA damage. We show that to counteract the GPx activity losses, the epididymis of the double $\mathrm{KO}$ animals mounted an antioxydant response resulting in a strong increase in the global $\mathrm{H}_{2} \mathrm{O}_{2-}$ scavenger activity especially in the cauda epididymis. Quantitative RT-PCR data show that together with the up-regulation of epididymal scavengers (of the thioredoxin/peroxiredoxin system as well as glutathione-S-transferases) the epididymis of double mutant animals increased the expression of several disulfide isomerases in an attempt to recover normal disulfidebridging activity. Despite these compensatory mechanisms cauda-stored spermatozoa of double mutant animals show high levels of DNA oxidation, increased fragmentation and greater susceptibility to nuclear decondensation. Nevertheless, the enzymatic epididymal salvage response is sufficient to maintain full fertility of double KO males whatever their age, crossed with young WT female mice.
\end{abstract}

Citation: Noblanc A, Peltier M, Damon-Soubeyrand C, Kerchkove N, Chabory E, et al. (2012) Epididymis Response Partly Compensates for Spermatozoa Oxidative Defects in snGPx4 and GPx5 Double Mutant Mice. PLoS ONE 7(6): e38565. doi:10.1371/journal.pone.0038565

Editor: Alexander James Roy Bishop, University of Texas Health Science Center at San Antonio, United States of America

Received March 16, 2012; Accepted May 7, 2012; Published June 14, 2012

Copyright: (C) 2012 Noblanc et al. This is an open-access article distributed under the terms of the Creative Commons Attribution License, which permits unrestricted use, distribution, and reproduction in any medium, provided the original author and source are credited.

Funding: Institutional funding from the CNRS, the INSERM and The French Ministry of Higher Education. The funders had no role in study design, data collection and analysis, decision to publish, or preparation of the manuscript.

Competing Interests: JRD is a PLoS ONE Editorial Board member. This does not alter the authors' adherence to all the PLoS ONE policies on sharing data and materials.

* E-mail: joel.drevet@univ-bpclermont.fr

\section{Introduction}

In mammalian reproduction, either naturally or by assisted reproductive technologies (ART), gamete quality is a key criterion. Sperm DNA integrity is a particularly important parameter concerning the contribution of the male gamete to successful reproduction. There are many reports of adverse clinical effects including depressed fertility, an increased incidence of miscarriage, and offspring morbidity following degradation of paternal chromosomes [1-13]. To avoid these potentially adverse conditions, eutherian mammals evolved elaborate processes to protect the paternal chromosomes from loss of integrity, the most obvious being the highly compacted state of the sperm nucleus. Sperm nucleus compaction is a process that is mainly achieved during testicular spermiogenesis by the extensive replacement of nuclear histones by smaller basic proteins, the protamines [14,15]. During the drastic cytodifferentiation step occurring at the end of mammalian spermatogenesis, compaction of the sperm haploid genome to approximately one tenth the size of the nucleus of any somatic cell serves two major purposes. It provides optimal velocity of spermatozoa and protects the paternal chromosomes from mutagenic effects of both intrinsic and extrinsic origins. At the end of the testicular spermatogenetic program, sperm nucleus compaction is not complete, but proceeds further as spermatozoa pass through the epididymis tubule. During this posttesticular step of sperm maturation, increased nucleus compaction is achieved by osmotic regulation/water resorption and intense disulfide bridging of thiol-containing protamines [1623].

The recent generation of knockout mouse models has allowed a better understanding of how disulfide-bridging events drive this aspect of post-testicular sperm nucleus enhanced compaction. Bi-functional glutathione peroxidase enzymes that can work either as $\mathrm{H}_{2} \mathrm{O}_{2} / \mathrm{LOOH}$-recycling enzymes or disulfide isomerases were shown to play key roles in this process. On the one hand, mice lacking the sperm nucleus-located isoform of glutathione peroxidase 4 ( $\operatorname{snGPx} 4$, a selenium-dependent GPx) present a delay in post-testicular (i.e., proximal epididymis) sperm nuclear compaction [24]. This phenotype demonstrated snGPx4 to be an active disulfide isomerase whose task is to increase sperm nucleus compaction through $\mathrm{H}_{2} \mathrm{O}_{2}$-mediated 
(or/and LOOH-mediated) oxidation of protamines during early spermatozoa epididymal journey [24,25]. On the other hand, we have shown previously that deletion of the epididymal luminal $\mathrm{H}_{2} \mathrm{O}_{2}$-scavenger ( $\mathrm{GPx} 5$, a selenium-independent $\mathrm{GPx}$ ) resulted in a transient increase in caput epididymal sperm DNA compaction [26]. This effect probably resulted from increased protamine disulfide-bridging via snGPx4 because of the luminal increase in $\mathrm{H}_{2} \mathrm{O}_{2}$ and/or LOOH availability due to the lack of GPx5 activity [26,27]. Thus, we have proposed that GPx5 via its epididymal luminal scavenger function acts as a coordinator enzyme that controls the concentration of $\mathrm{H}_{2} \mathrm{O}_{2} / \mathrm{LOOH}$ in the caput lumen, thereby defining the optimal disulfide-bridging activity of snGPx4 in the caput territory. In addition, throughout the epididymis and especially in the cauda territory, the ROS-scavenging function of GPx5 protects epididymal transiting and cauda-stored spermatozoa form oxidative injuries $[26,27]$. To analyze further the importance of these two enzymes in the physiology of the epididymis and in sperm maturation, we have generated transgenic mice lacking both snGPx4 and GPx5. We present here the epididymal and spermatozoa phenotypes of these double mutant animals.

\section{Results}

Generation of Double Transgenic sngpx4;gpx $5^{-/-}$Mice

Null mice for snGPx4 and GPx5 were generated following crosses of inbred sngp $x 4^{-/-}$animals [24] and $g p x 5^{-/-}$animals [26] that were initially produced in the same C57bl/6 genetic background. Genotyping data shown in Figure 1 illustrate that the homozygous derived sngp 4 ; $g p \times 5^{-1-}$ animals carry the transgenic constructs and, therefore, are devoid of functional snGPx4 and GPx5 genes. As for each single KO, simultaneous sngpx4 and $g p x 5$ inactivation had no impact on the organization of the epididymis tissue (as evidenced by histological observation) or caput or cauda sperm counts (monitored at 4 months of age), suggesting that lack of snGPx4 and GPx5 expression does not affect sperm production and epididymal transit and function (not shown).

\section{Spermatozoa of Double Mutant Male Mice Show Impaired Sperm DNA Compaction}

As shown by toluidine blue staining in caput and cauda sperm of the double $\mathrm{KO}$ animals at 4 months and 8 months of age, a large proportion (up to $80 \%$ ) of the double mutant caput sperm population showed defective nuclear condensation (Figure 2A and 2B). However, sperm DNA compaction resumed an apparently normal level in cauda-collected spermatozoa of the double mutants (Fig. 2C).

\section{Impaired Sperm DNA Compaction in the Double Mutant Animals is Associated with a Giant Head Sperm Phenotype}

Shorr staining (Figure 3A) showed that 30 to $35 \%$ of the caput sperm population had a giant head phenotype irrespectively of mice age ( 4 or 8 months, Figure 3B). Again, this is a caput restricted sperm phenotype, because less than $0.2 \%$ of the cauda sperm population exhibited this morphological alteration (data not shown). Using PNA-Alexa and Hoechst staining to detect the acrosomal and the nuclear sperm compartments, respectively, we show in Figure $3 \mathrm{C}$, that the giant sperm head phenotype of the double mutant mice was essentially due to nuclear expansion (as evidenced by the Hoechst staining) while the acrosome-staining was not dramatically different from that of the WT spermatozoa.

\section{Nuclear Susceptibility to Reducing Conditions of Double Mutant Cauda Spermatozoa}

Although sperm nucleus size was similar to that of WT in the cauda compartment of double mutant animals (see Figure 2C), Figure 4 shows that these spermatozoa remained very sensitive to reducing conditions such as treatment with dithiotreitol (DTT). When applied on cauda-retrieved double mutant spermatozoa, it provoked nuclear expansion and the reappearance of the giant head phenotype for a larger proportion of spermatozoa compared to WT animals. This data reveals that cauda sperm nuclei of double mutant animals did not reach their optimal and solid condensed state compared to WT animals.

\section{Nuclear Expansion in Spermatozoa of Double Mutant Animals is neither Due to Defective Protamination nor to Decreased Disulfide Bridging}

Since we recorded no differences in the spermatozoa phenotype of the double mutant animals at 4 and 8 months, all further experiments were carried out on spermatozoa from animals aged 4 months. Because snGPx4 is located in the sperm nucleus during spermiogenesis, it may be argued that its absence could somehow impair the process of histone replacement by protamines, eventually leading to defective sperm nuclear protamination in the double mutant. We used flow cytometry and chromomycin A3 as a probe to evaluate indirectly the protamine content of WT and double mutant spermatozoa. Figure 5A first shows that sperm nuclear compaction was increased during spermatozoa epididymal journey from the caput to the cauda irrespective of the genetic background. This Figure also indicates that there was no significant difference in the percentage of recorded fluorescence due to chromomycin A3 staining both in caput and cauda double mutant spermatozoa when compared to WT spermatozoa. Defective testicular protamination is therefore unlikely to explain sperm nuclear decondensation in the double mutants.

To obtain an evaluation of epididymal disulfide-bridging activity, flow cytometry and a monobromobimane probe were used to monitor the free thiol content of sperm proteins in WT and double mutant animals. Figure 5B first illustrates increase in sperm disulfide-bridging events during spermatozoa epididymal journey from the caput to the cauda irrespective of the genetic background. In addition, and in contrast to what might have been logically expected in a context of defective snGPx4 disulfide bridging activity, Figure $5 \mathrm{~B}$ also shows that caput and, to a lesser extent cauda sperm samples of double mutant animals, contained less free thiol groups than WT controls. Since monobromobimane staining is inversely correlated with the number of disulfides, these data suggest that increased disulfide-bridging events took place in the epididymis (particularly in the caput compartment) of double mutant animals despite the absence of the snGPx4 player. This suggests that the epididymis of the double mutant animal has somehow found a way to enhance its global disulfide isomerase activity.

\section{The Epididymis of Double Mutants Compensates for the Lack of ROS-scavenging Activity}

Figure $6 \mathrm{~A}$ shows that in the double mutant animals, global $\mathrm{H}_{2} \mathrm{O}_{2}$-scavenging activity was up-regulated especially in the cauda compartment. The global $\mathrm{H}_{2} \mathrm{O}_{2}$-scavenging activity recorded in the double mutant cauda territory exceeded by far that recorded in the same compartment in WT animals. As a physiological indicator, Figure $6 \mathrm{~A}$, also shows that the global $\mathrm{H}_{2} \mathrm{O}_{2}$-scavenging activity recorded in the epididymis of double mutant animals was quite comparable to that found in liver, a tissue well-known for its 


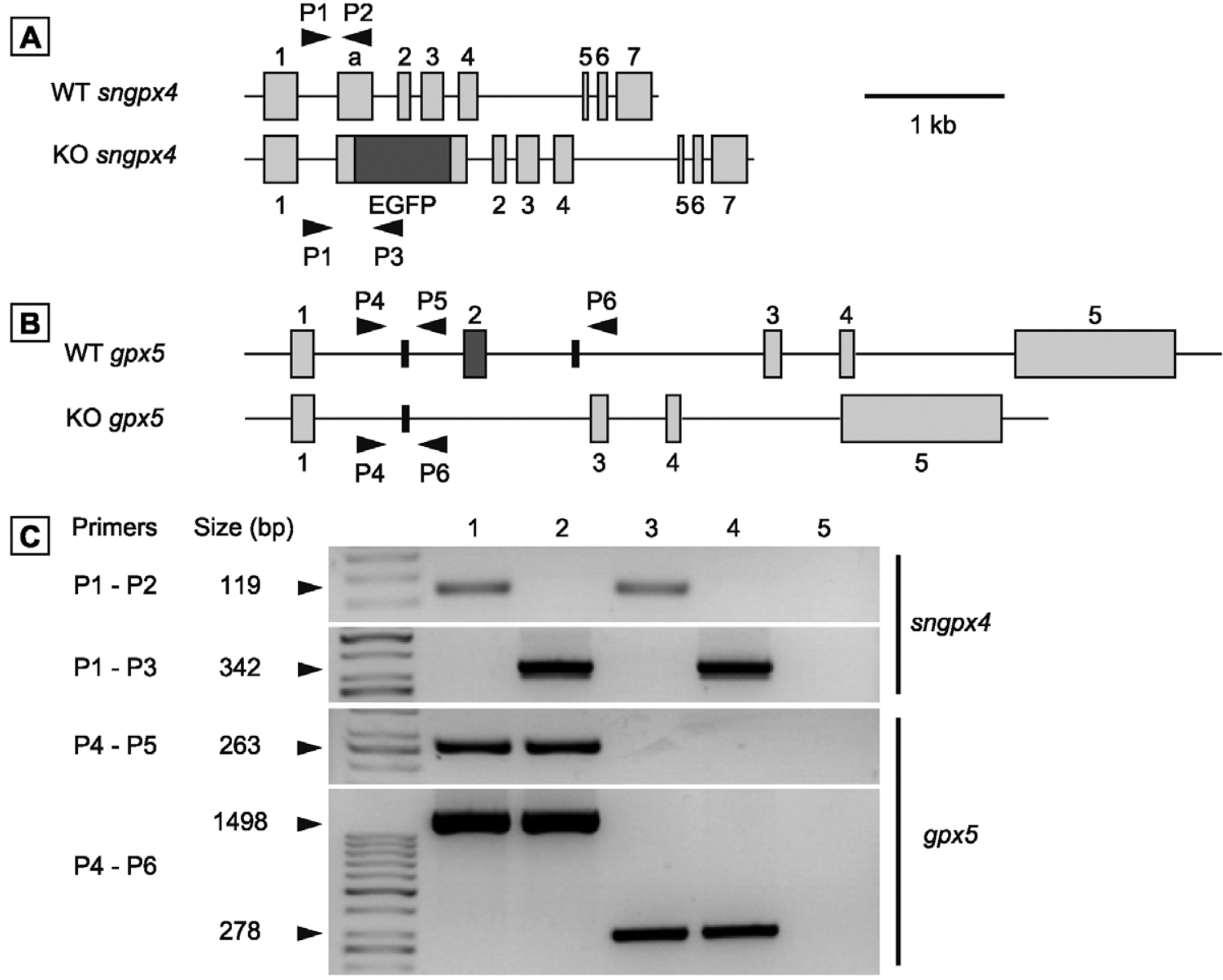

Figure 1. Generation of sngpx4;gpx5-deficient mice. A and B: Diagramatic representations of mouse GPx4 (A) and GPx5 (B) gene organization (upper diagrams in $A$ and $B$ ) and of their engineered version found in the single KO animals (lower schemes in $A$ and $B)(1,20)$. Transgenic sngpx $4^{-1-}$ animals bear an EGFP reporter cassette (20), while transgenic $g p \times 5^{-/-}$animals carry a deleted exon 2 (1). Grey boxes (1,a and 2 to 7 for sngpx4 and 1 to 5 for $g p \times 5)$ indicate the 8 or 5 coding exons, respectively. Bold arrowheads indicate the relative positions of the various primers used thereafter in genotyping PCR amplifications. C: Typical PCR experiments carried out on genomic DNA extracted from animal fingers used to select homozygous sngp $x 4 ; g p \times 5^{-1-}$ (DKO) animals. Size (in bp) of the expected PCR products for each primer pair used is given in the left margin. The two upper panels show sngpx4 amplifications, while the two lower panels show gpx5 amplifications. Lane 4 (DKO) stands for double knock-out animals, while lane 5 is a negative control in which no genomic DNA was added to the reactions. Primer sequences are given in Table 2. Lanes 1, 2 and 3 are positive control

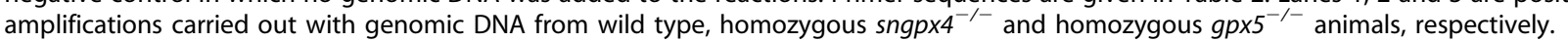
doi:10.1371/journal.pone.0038565.g001

high ROS-recycling metabolism. It is also important to note that, in the double mutant animals, the epididymis but not the liver was engaged in this global antioxidant response. As a result, the content in malonyldialdehyde (MDA), an end-point marker of lipid peroxidation, was significantly lower in spermatozoa of double mutant animals when compared to WT (Figure 6B). In caput and cauda tissue extracts, the MDA content was similar when WT samples were compared to KO samples. This suggests that the surnumerary protection against lipid peroxidation engaged by the cauda epididymis was of a secreted nature or already present in the vicinity or on the sperm cell itself.

Both $\mathrm{H}_{2} \mathrm{O}_{2}$ Scavengers and Disufilde Isomerases are Upregulated in the Epididymis of the Double Mutant Animals

To determine which ROS-recycling enzyme(s) and disulfidebridging enzymes(s) were up-regulated in the epididymis of the double mutant animals, we used qRT-PGR to monitor the expression of various genes encoding these classes of proteins (see
Table 1) in the caput and cauda epididymidis compartments of WT and double mutant male mice. Concerning ROS-recycling enzymes (ROS-scavengers) we found that overexpression of the classical cauda epithelial GPxs (ie. GPx1, GPx3 and the cellular isoform of GPx4 [cGPx4]) as well as catalase, all being cytosolic enzymes, were not responsible for the extra scavenging capacity of this territory in the double mutant animals. Surprisingly, we even recorded a decrease in the expression of these classical $\mathrm{H}_{2} \mathrm{O}_{2}$ - or/ and LOOH-recycling GPx genes both in the caput and cauda territories of the double mutant animals compared to WT. The extra $\mathrm{H}_{2} \mathrm{O}_{2}$ (or LOOH) recycling/consuming activities switched on in the epididymis of the double mutant animals were therefore not of the classical GPx/Catalase types. Rather, glutathione S transferases (GST $\mu$ and GST $\pi$ ), a peroxiredoxin (PRDX3) and thioredoxin/thioredoxin-like genes such as TXN1 and TXNL1 were found up-regulated in the epididymis of the double mutant animals. We recorded some regional differences in the overexpression of these ROS-recycling activities since TXNL1 overexpression appeared to be a caput-restricted response while TXN1 and PRDX3 overexpression were recorded solely in the cauda 


\section{A}

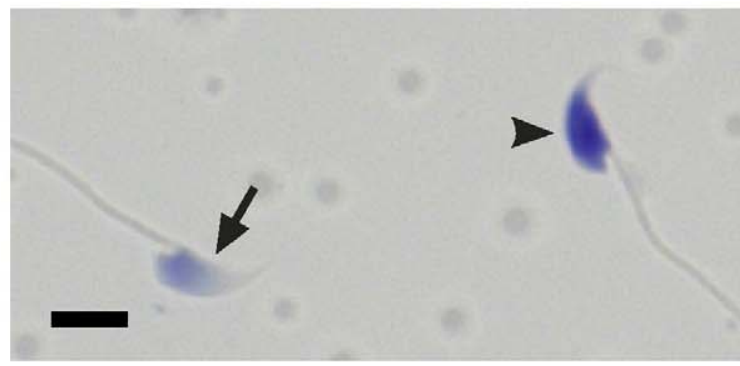

B

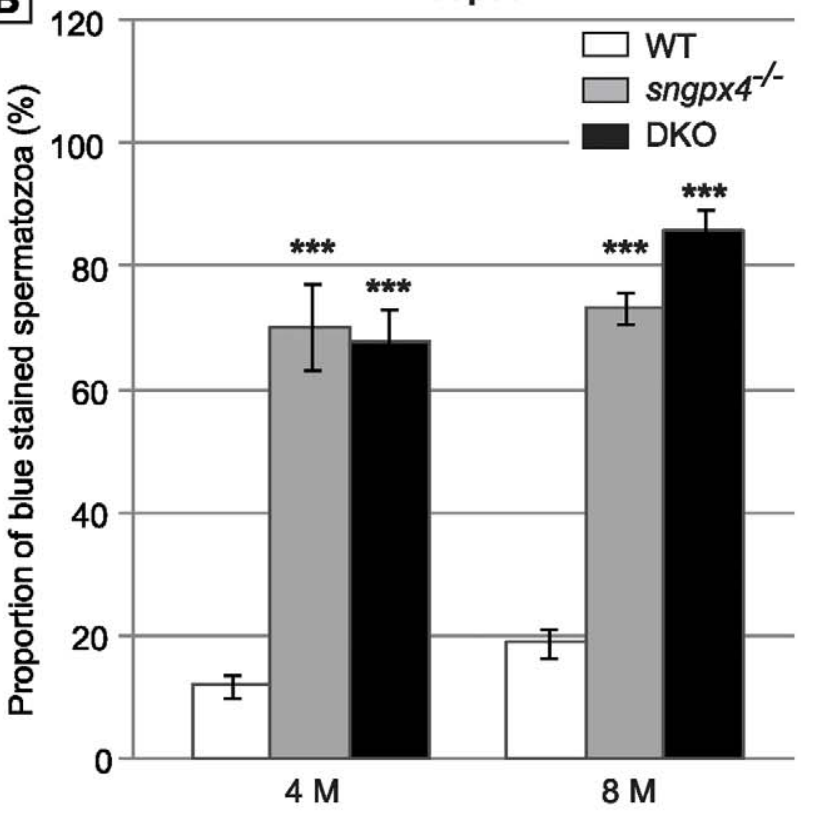

C

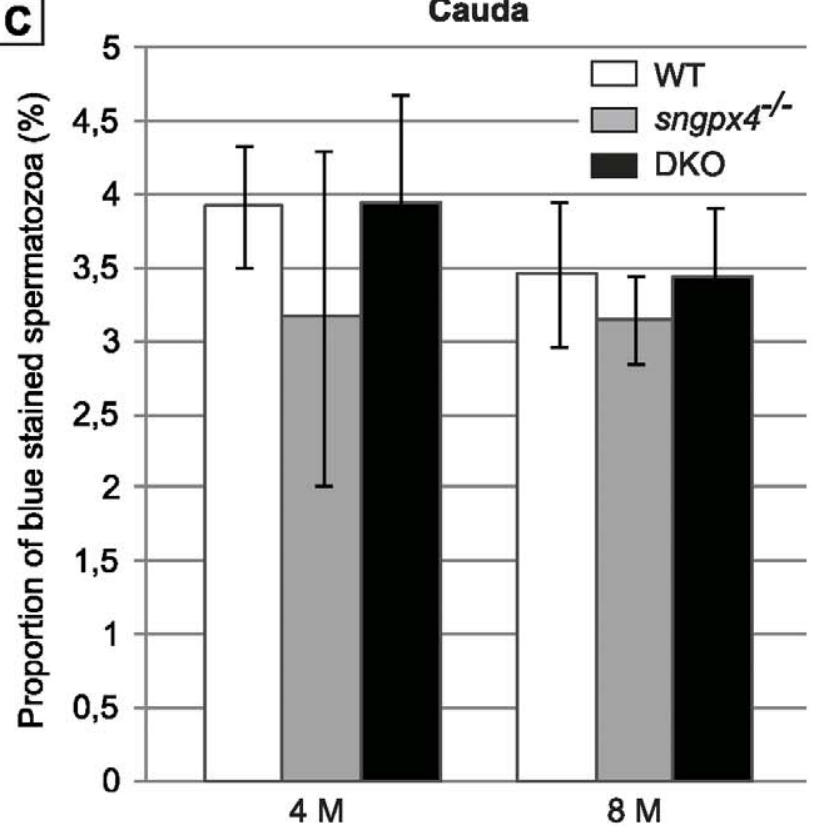

Figure 2. Evaluation of sperm DNA condensation using toluidine blue staining. A: The photograph shows a typical result of toluidine blue staining on a decondensed caput sperm DNA (arrowhead) compared to a condensed caput sperm DNA (arrow). Scale bar $=5 \mu \mathrm{m}$. B and C: Histograms plotting the proportion of decondensed sperm nucleus found in WT, sngp $\times 4^{-/-}$and DKO caput sperm population (B) and cauda sperm population (C) in animals aged 4 or 8 months. (Mean $+/-$ SEM; $n=5 ; * * *: p \leq 0.001$ compared to WT). doi:10.1371/journal.pone.0038565.g002

territory. Regarding the response of the epididymis in terms of disulfide-bridging activities, we monitored the expression of several classical disulfide isomerases and we show in Table 1 that PDIA3 (ERP57), PDIA5, PDIA6 (TXNDC7), PDIA10 (ERP44/ TXNDC4) and PDIA11 (TXNDC1) were up-regulated in caput and/or cauda tissue samples of the double mutant animals compared to WT.

\section{Spermatozoa of Double Mutant Animals Show Increased DNA Fragmentation associated with DNA Oxidative \\ Damage}

Based on a modified method of the classical sperm chromatin dispersion assay (SCDA, [28]) Figure 7A illustrates that cauda spermatozoa of double mutant animals presented a higher level of DNA fragmentation than WT spermatozoa at the same ages. Figure $7 \mathrm{~B}$ also shows that for double mutant animals aged 4 months the level of sperm DNA oxidative damage was well controled by the epididymis antioxidant response since cauda spermatozoa were as reactive to an 8 oxo-dG antibody as WT spermatozoa. However, the situation was rather different with spermatozoa collected from older double mutant animals (8 months) where a high proportion of spermatozoa revealed oxidized guanine residues typical of DNA oxidative alterations. Figure 7C shows that this weaker protection of cauda collected spermatozoa in older animals was probably due to a general physiological decrease in the cauda epididymidis antioxidant response since we show that at this age (8 months), global $\mathrm{H}_{2} \mathrm{O}_{2}$ /LOOH-recycling activity was reduced by 2.5-fold both in WT and double mutant cauda epididymidis protein extracts compared to the situation in animals aged 4 months.

\section{The Epididymis Antioxidant Response in the Double Mutant is Sufficient to Preserve Fertility}

To investigate the effect of the absence of snGPx4 and epididymal GPx5 expression on male fertility, mice of both genotypes (wt and sngpx4;gpx5-/-) were mated with wt female $\mathrm{C} 57 \mathrm{Bl} / 6$ mice. Mating was conducted with animals at optimal reproductive age (3 months). No changes in mating behaviour were noticed. Three-month old double mutant male mice were found fertile with litter sizes (pups $8.00 \pm 0.52, \mathrm{n}=6$ ) comparable to those of WT mice at the same age (pups $8.17 \pm 0.48, \mathrm{n}=6$ ) (Figure 8A). More crosses were carried out with older male mice and wt young females to determine if the absence of both GPx had a greater effect after aging. Figure 8A shows that in males up to 17 months of age there were no statistically significant differences in litter sizes between sngpx4;gpx5-/- and WT backgrounds. Time to gestation was also monitored and found to be comparable to that of WT crosses (Fig. 8B). Number of dead pups and perinatal mortality were monitored for each cross and found to be statistically comparable in WT and double mutant animals (Fig. 8C).

\section{Discussion}

We and other authors, have already proposed that sperm nuclear compaction is enhanced during epididymal descent by the combined actions of the snGPx4 disulfide isomerase and the luminal epididymal GPx5 scavenger that control $\mathrm{H}_{2} \mathrm{O}_{2}$ (or $\mathrm{LOOH}$ ) availability, therefore determining the level of disulfidebridging events on thiol-containing sperm protamines [24-27]. 

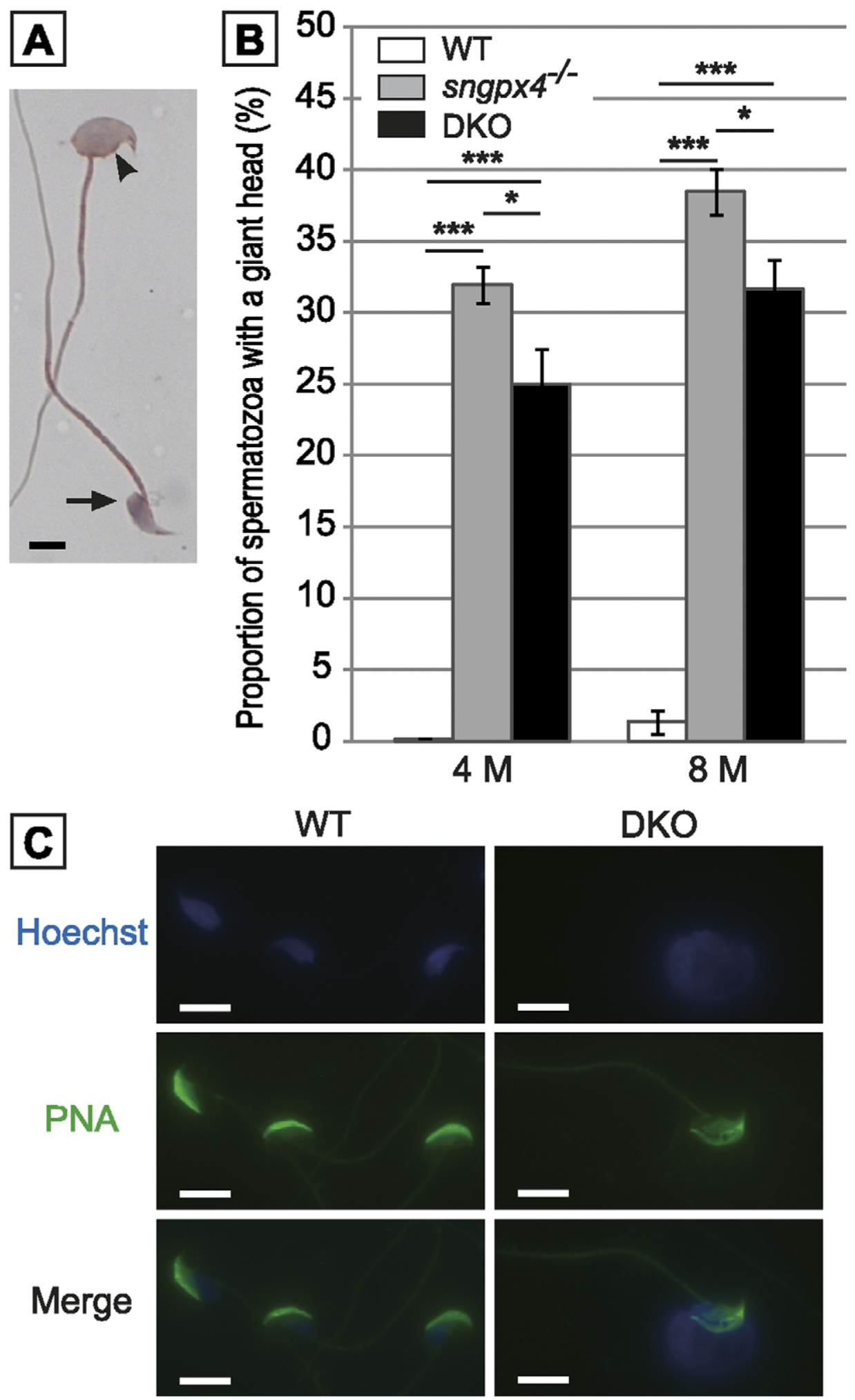

Figure 3. Morphological evaluation of caput sperm heads using Schorr staining. A: Photograph shows sperm head morphology with (arrowhead) or without (arrow) alterations found in caput epididymidis. Scale bar $=5 \mu \mathrm{m}$. B: Histograms plotting the proportion of caput sperm showing a giant head phenotype in WT, sngp $4^{-/-}$and DKO animals aged 4 or 8 months. (Mean $+/-$ SEM; $n=5 ; * * *: p \leq 0.001$ compared to WT) C: Micrographs show WT (left panels) and DKO (right panels) caput spermatozoa stained either with Hoechst to localize the nucleus compartment (upper panels) or with PNA-Alexa488 to visualize the acrosome compartment (median panels). PNA-Alexa488 and Hoechst stains are merged on the lower panels. Scale bar $=5 \mu \mathrm{m}$.

doi:10.1371/journal.pone.0038565.g003 


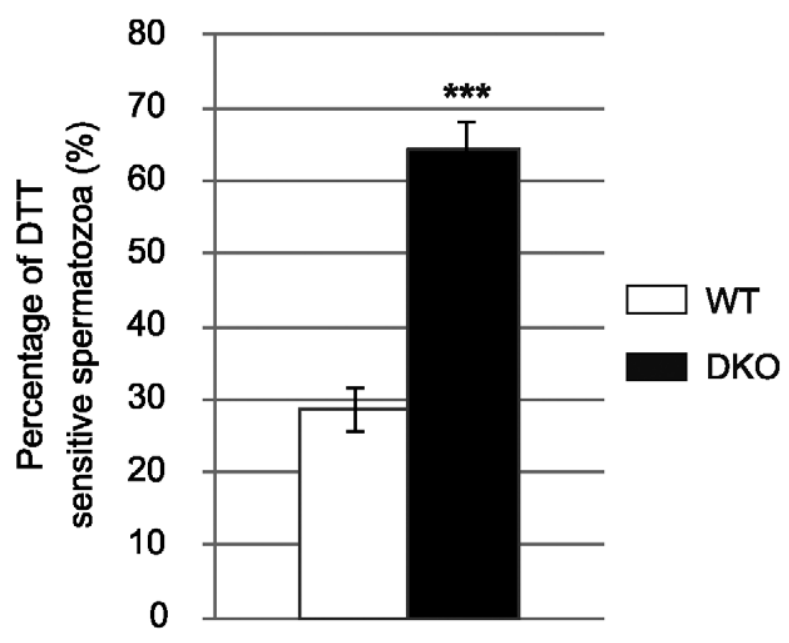

Figure 4. DKO cauda spermatozoa fragility. Histograms showing the proportion of WT and DKO cauda spermatozoa with a giant head phenotype after treatment of the sperm preparations with $2 \mathrm{mM}$ DTT. (Mean +/- SEM; $\mathrm{n}=5 ;{ }^{* * *}$ : $\mathrm{p} \leq 0.001$ compared to WT).

doi:10.1371/journal.pone.0038565.g004

We report here on the generation of a mouse strain in which both GPxs (snGPx4 and GPx5) were invalidated. In agreement with the tissue- and cell-restricted expression of both genes, and similarly to each single knock-out, lack of snGPx4 and GPx5 expression has no impact on animal viability. Using light microscopy, we recorded no difference in the organization and cytology of epididymal and testicular tissues of the double mutant animals when compared to WT animals (not illustrated). In addition, sperm cell number and sperm cell viability were found to be identical to those of control animals regardless of age. Since we expected from the respective single knock-outs $[25,26]$ that spermatozoa from the double mutant animals would present nuclear structural defects, we focused our investigation on caput and cauda spermatozoa of the double mutants. We first show that already at 4 months of age and as early as in the caput territory about $80 \%$ of double mutant spermatozoa are concerned by nuclear decompaction. Compared to the single $g p \times 5^{-1-}$ model, the situation in the double mutant is rather different since caput sperm of $g p \times 5^{-/-}$animals showed increased nuclear compaction attributed to a higher availability of $\mathrm{H}_{2} \mathrm{O}_{2} / \mathrm{LOOH}$ for the disulfide bridging activity of the snGPx4 enzyme [26]. The situation is however identical to that of caput spermatozoa of the single sngp $\times 4^{-/-}$strain at the same age as reported earlier by Conrad et al (2005) [25]. These data suggest that in the caput territory of the double mutant animals, lack of GPx5 activity does not worsen the state of sperm nuclear compaction observed in the single sngp $x 4^{-/-}$model [24]. Alternatively, it may also indicate that defective GPx5 ROSscavenging function has been compensated by other means in the double mutant animals. This is supported by our observations that several enzymatic scavengers are up-regulated both in the caput and the cauda epididymis of the double mutant animals compared to WT controls.

The nuclear decompaction we observed in caput-collected sperm of the double mutants was found to be transient since an apparently normal WT-like nuclear compaction was seen in cauda sperm, a situation also reported earlier for the snGPx4 KO [24,29]. We show here that low caput sperm nuclear compaction was associated with a giant-head phenotype affecting one third of the caput sperm population. We also show that this giant-head sperm phenotype is correlated with nuclear decondensation. Sperm nuclear instability in the double mutant was not due to defective protamination or to decreased disulfide-bridging. On the contrary, for the latter, despite the absence of the snGPx4 disulfide isomerase activity, total sperm disulfide content was significantly greater in double mutants than in control WT animals, especially in the caput compartment. This observation again supports the idea that other activities, probably disulfide isomerases, have been switched-on to compensate for the absence of snGPx4 during spermatozoa epididymal transit in the double mutant animals. In agreement with this hypothesis we found that several protein disulfide isomerases or PDI-related proteins were up-regulated both in the caput and in the cauda compartments of the double mutant animals. Namely, PDIA3 (ERP57), PDIA5, PDIA6 (TXNDC7), PDIA10 (TXNDC4/ERP44) a PDI-chaperone protein which was shown to be involved in the control of oxidative protein folding [30] and PDIA11 (TCXNDC1), were found significantly up-regulated in the epididymis of the double mutant animals. These protein disulfide isomerases are already known to be expressed at significant levels in the mouse epididymis [31]. In particular, PDIA5 over-expression in the epididymis of the double mutant animals could be a logical response of the tissue to the absence of the caput active snGPx4 because PDIA5 was reported to be preferentially expressed in the distal caput epididymis [31]. Although the increase in protein disulfide isomerase expression allowed recovery of a normal nuclear compaction state in cauda-stored spermatozoa of double mutant animals we show here that the nucleus of these spermatozoa still remained fragile when challenged by a reducing agent such as DTT. DTT treatment of spermatozoa provoked the reappearance of the giant-head phenotype in two-third of the cauda sperm population in 4 month-old double mutant animals, while only $25 \%$ of WT cauda-stored spermatozoa were reactive to this treatment. As in the caput compartment of double mutants, the giant-head phenotype of cauda spermatozoa was shown to be associated with nuclear decondensation. These data are in agreement with a very recent report on sngpx $4^{-1-}$ sperm nuclei which were also found to be susceptible to provoked decondensation [29]. Therefore, despite higher disulfide-bridging events due to the increase in protein disulfide isomerase expression along the epididymal tubule of the double mutant animals, sperm nuclei did not reach its WT-type-like optimal condensed state. This may be related to the inability of these induced disulfide isomerases to work in the sperm nucleus. In addition, it is also possible that cauda sperm DNA instability in the double mutant results from an increase in ROS-mediated DNA alterations (from DNA oxidation to DNA breaks) due to the pro-oxidant environment (i.e., because of the lack of GPx5). This would be comparable to the cauda sperm phenotype reported earlier in the single GPx5 KO [26]. Our data reinforces the idea that an optimal epididymal disulfide crosslinking activity is important to "shield" sperm nucleus against ROS-induced DNA damage. The duality of the situation is that the epididymis uses $\mathrm{H}_{2} \mathrm{O}_{2} / \mathrm{LOOH}$ to promote sperm-nucleus GPx4 disulfide isomerase activity even though spermatozoa are particularly sensitive to ROS. One explanation may reside in the fact that only a permeant agent such as $\mathrm{H}_{2} \mathrm{O}_{2}$ has the ability to reach the already quite condensed sperm nucleus compartment.

Concerning the antioxidant response of the epididymis in the double mutant, we show here that there was a large increase in $\mathrm{H}_{2} \mathrm{O}_{2}$-scavenging activity especially in the cauda epididymis of the double mutant. Total $\mathrm{H}_{2} \mathrm{O}_{2}$-recycling capacity in the cauda epididymis of the double $\mathrm{KO}$ animals was such that it reached 


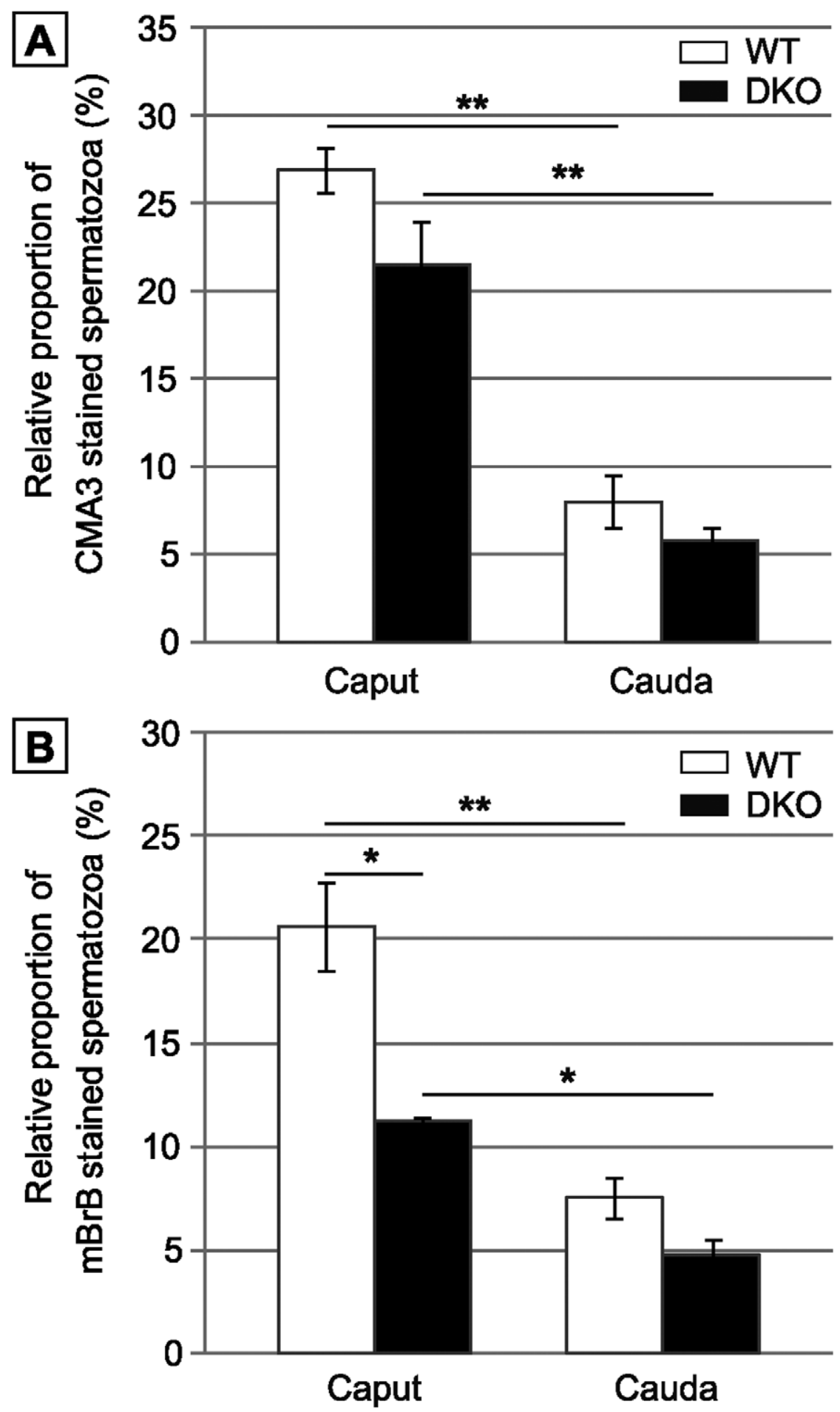

Figure 5. Evaluation of spermatozoa integrity by flow cytometry. A: Protamine association with sperm chromatin determined by chromomycin A3 (CMA3) staining. Histograms show the proportion of CMA3 incorporated in caput and cauda sperm of WT versus DKO animals aged 4 months. B: Disulfide bonds/free thiol quantification by monobromobimane $(\mathrm{mBrB})$ staining. Histograms showing the incorporation of $\mathrm{mBrB}$ in caput and cauda sperm of WT versus DKO animals aged 4 months. (Mean $+/-$ SEM; $n=6 ;{ }^{*}: p \leq 0.05 ;{ }^{* *}: p \leq 0.01$ ). doi:10.1371/journal.pone.0038565.g005

and even exceeded the $\mathrm{H}_{2} \mathrm{O}_{2}$-scavenging activity recorded in liver, a tissue that has a considerable $\mathrm{H}_{2} \mathrm{O}_{2}$-recycling coverage because of its high detoxification metabolism. In comparison, global GPx-like activity in cauda epididymidis extracts of the single GPx5 KO animals was reported earlier to be identical to that of the WT controls [26]. Interestingly, in the earlier model, the maintenance of normal $\mathrm{H}_{2} \mathrm{O}_{2}$-scavenging activity in the cauda epididymis was shown to be due to the transcriptional upregulation of the epithelial cytosolic GPxs (GPx1, GPx3 and cGPx4) as well as catalase [26]. We show here that the adaptive 

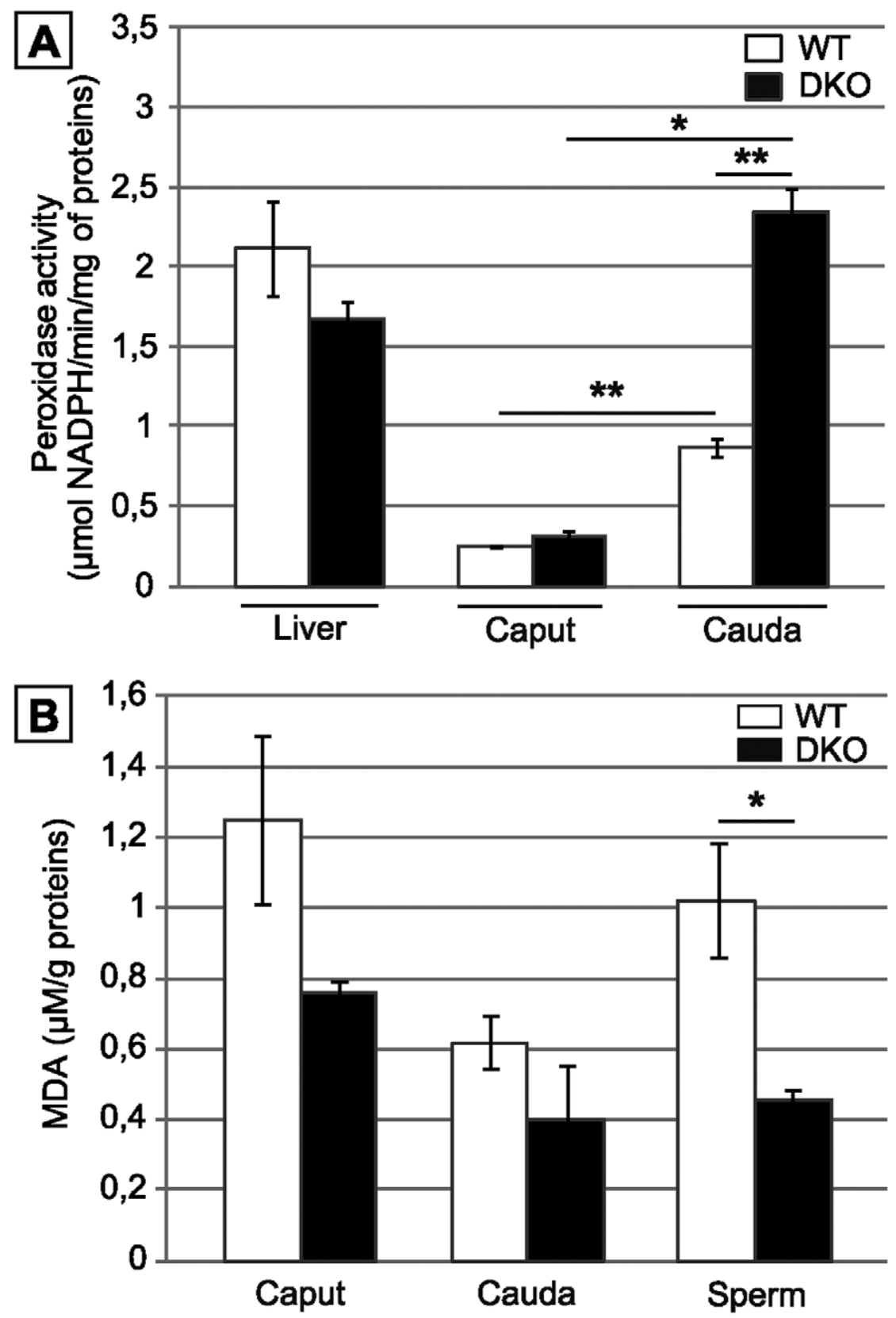

Figure 6. snGPx4;GPx5 deficiency leads to a strong epididymis anti-oxidant response. A: Histograms show global $\mathrm{H}_{2} \mathrm{O}_{2}$-scavenging activity using $\mathrm{H}_{2} \mathrm{O}_{2}$ as a substrate in caput or cauda epididymis tissue extracts from WT or DKO animals aged 4 months. To evaluate the extent of the epididymis anti-oxidant response global $\mathrm{H}_{2} \mathrm{O}_{2}$-scavenging activity in liver extracts of the same animals are shown on the left. (Mean $+/-\mathrm{SEM} ; \mathrm{n}=5$; **: $p \leq 0.01$ compared to WT) B: Malondialdehyde (MDA) measurements on caput and cauda epididymal tissues as well as on cauda-collected spermatozoa from WT and DKO animals aged 4 months. (Mean $+/-$ SEM; $n=3 ;{ }^{*}$ : $\mathrm{p} \leq 0.05$ compared to WT). doi:10.1371/journal.pone.0038565.g006

response of the epididymis in double mutant animals was different, because neither the cytosolic epithelial epididymal GPxs nor catalase were found to be transcriptionally upregulated. On the contrary, compared to control animals, accumulations of epididymal GPx transcripts and to a lesser extend catalase transcripts were significantly lower in the caput and cauda compartments of the double mutants. This behavior may be comparable with recent reports which have shown that prolonged/chronic ROS exposure contributes to the downregulation of GPx or catalase expression (for example see [32]). SOD3 expression was also found to be significantly reduced in the cauda epididymis territory of the double mutant animals. Since extracellular SOD activity contributes to the generation of luminal $\mathrm{H}_{2} \mathrm{O}_{2}$, it is possible that down-regulation of SOD3 expression is another method by which the epididymis of the double mutant animals regulates accumulation of this ROS around stored spermatozoa. These observations suggest that $\mathrm{H}_{2} \mathrm{O}_{2}$-recycling in the epididymis of the double mutant animals is ensured by other enzymes. In agreement with this hypothesis, we found that several scavengers were transcriptionally upregulated in the caput and cauda epididymidis compartments of the double mutant, including thioredoxins (TRX)/thioredoxin- 
Table 1. Evaluation of the expression of various ROSscavenger and disulfide isomerase genes using real-time PCR on tissue extracts of caput and cauda epididymidis from WT and DKO animals aged 4 months.

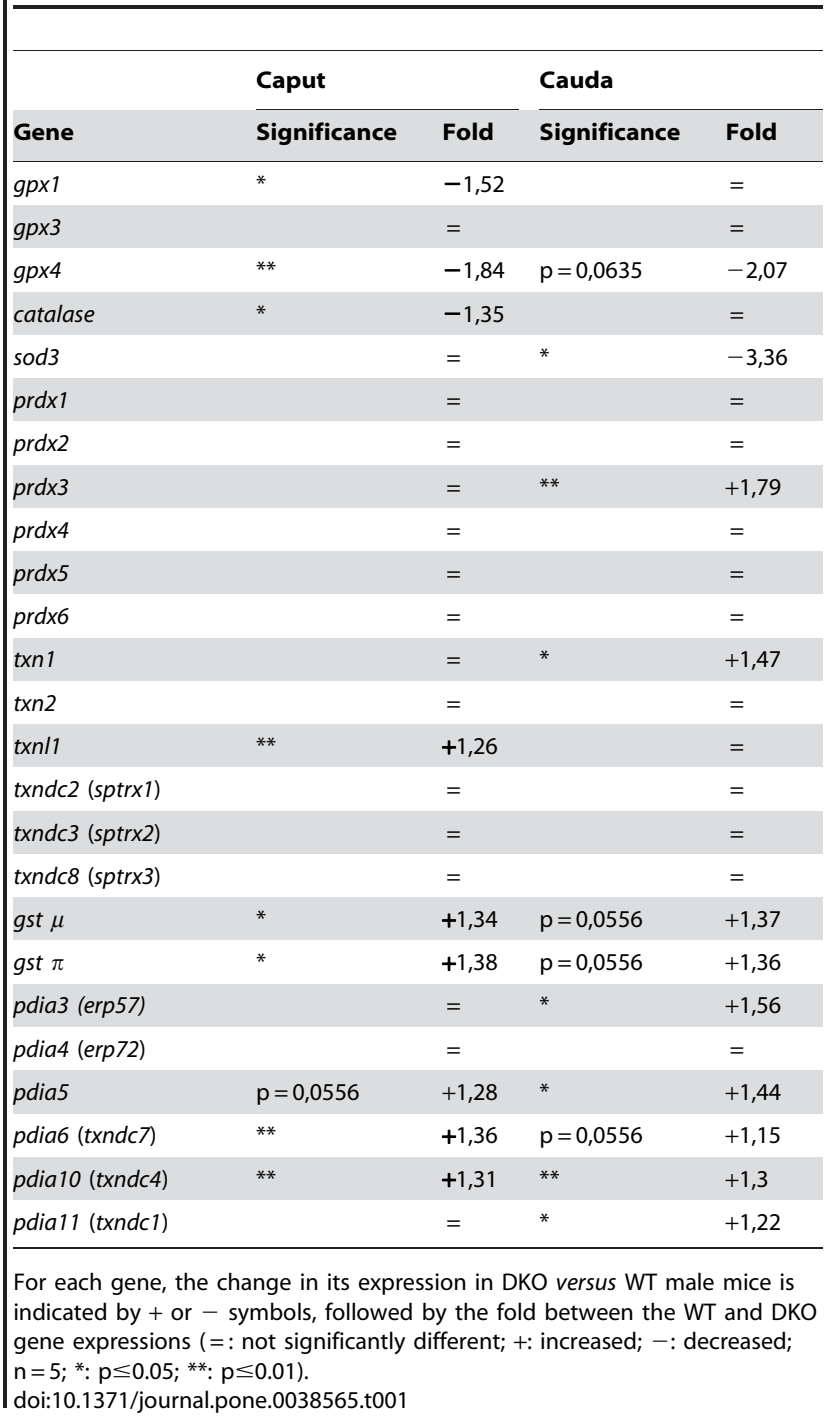

like proteins such as TXNl and TXNLl as well as a peroxiredoxin (PRX), PRDX3. The thioredoxin/peroxiredoxin (TRX/PRX) couple is the prevalent redox system occurring in a wide variety of tissues and cells [33,34]. Some PRX have been shown to be more efficient in neutralizing $\mathrm{H}_{2} \mathrm{O}_{2}$ than catalase and the glutathione/glutathione peroxidase (GSH/GPx) system $[35,36]$. It has also been reported that they are regenerated a lot faster than other redox proteins [37]. PRDX3 is a mitochondrial peroxidase that was shown in a different context, the eye lens epithelia, to be highly and specifically induced by low levels of $\mathrm{H}_{2} \mathrm{O}_{2}$ and as such, is considered as a gene acutely responsive to increased $\mathrm{H}_{2} \mathrm{O}_{2}$ levels [38]. Expression of PRX proteins throughout the mouse epididymis was reported earlier and PRDX3 is, together with PRDX1, PRDX5 and PRDX6, significantly expressed in the caput and cauda compartments [31]. Our analysis shows that only PRDX3, but not the other epididymis-expressed PRDXs, is up-regulated in the cauda territory of double mutant animals. Concerning thioredoxins, TXN1 was also reported to be significantly expressed throughout
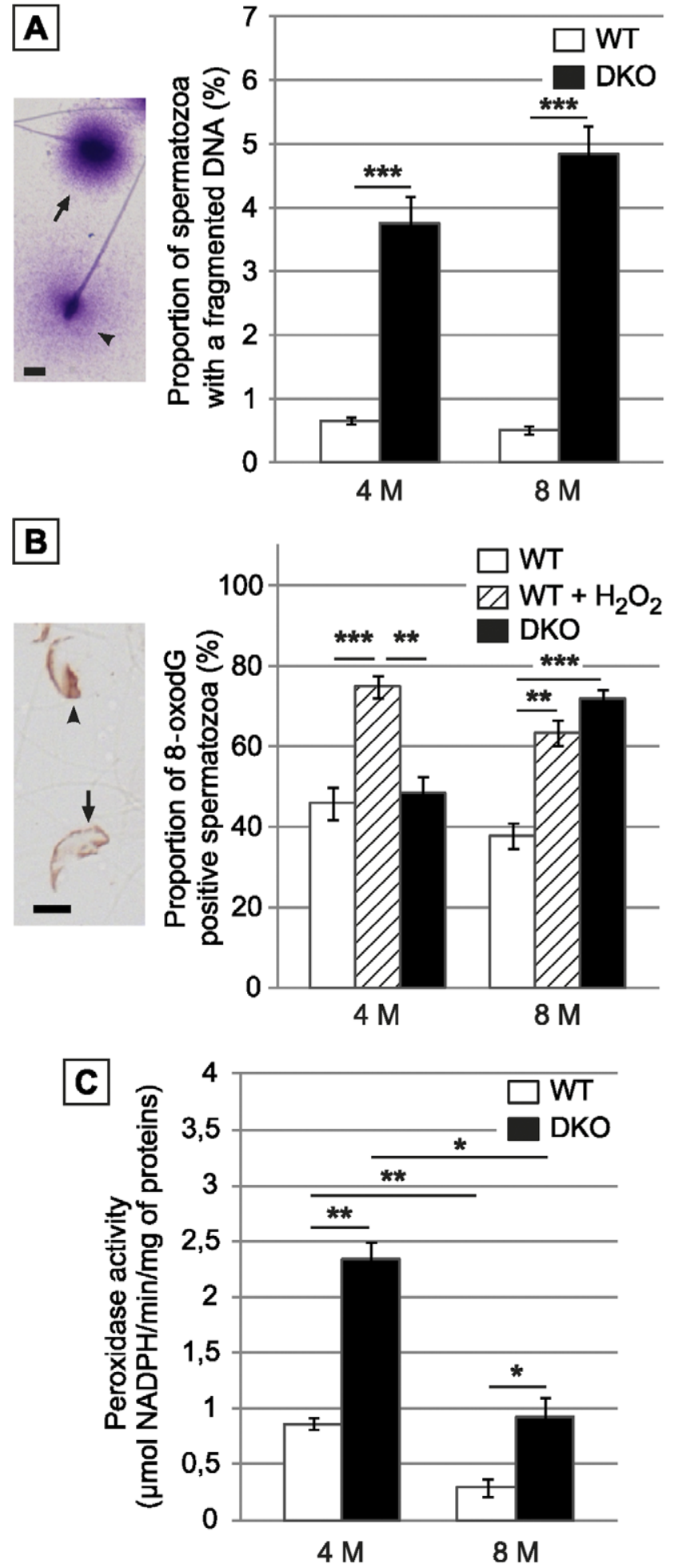

Figure 7. Cauda-retrieved spermatozoa of DKO animals suffer oxidative damage. A: Left panel: Typical picture of fragmented (arrowhead) or non-fragmented (arrow) sperm nucleus as shown by the modified Sperm Chromatin Dispersion Assay. Scale bar $=5 \mu \mathrm{m}$. Right panel: Histograms show the proportion of WT and DKO cauda collected spermatozoa with a fragmented DNA in animals aged 4 or 8 months. B: Left panel: Typical immunodetection of the nuclear adduct 8-oxodG in cauda epididymidis-retrieved spermatozoa preparations from DKO male mice aged 8 months. Scale bar $=5 \mu \mathrm{m}$. Right panel: Histograms show the percentage of 8-oxodG positive spermatozoa in cauda epididymi- 
dis-retrieved spermatozoa preparations, respectively from WT, positive control (WT spermatozoa treated with $\mathrm{H}_{2} \mathrm{O}_{2}$ ) and DKO male mice aged 4 and 8 months. (Mean+/-SEM; $n=5$; *: $p \leq 0.05$; **: $p \leq 0.01$; ***: $\mathrm{p} \leq 0.001)$. C: Histograms show global $\mathrm{H}_{2} \mathrm{O}_{2}$-scavenging activity using $\mathrm{H}_{2} \mathrm{O}_{2}$ as a substrate in cauda epididymidis tissue extracts from WT or DKO animals aged 4 or 8 months. (Mean $+/-\mathrm{SEM} ; \mathrm{n}=5$; ${ }^{*} \mathrm{p} \leq 0.05$; **: $\mathrm{p} \leq 0.01)$.

doi:10.1371/journal.pone.0038565.g007 the epididymis [31], while TXNL1 was found to be weakly expressed in that tissue [31]. Because of the low profile of the glutathione system in the epididymis, it would not be surprising that the TRX/PRX system may play a significant role in eliminating excess $\mathrm{H}_{2} \mathrm{O}_{2}$ in that compartment. The role of thioredoxin as electron donor in the epididymis has already been proposed when we showed earlier, that GPx5 is a selenium-
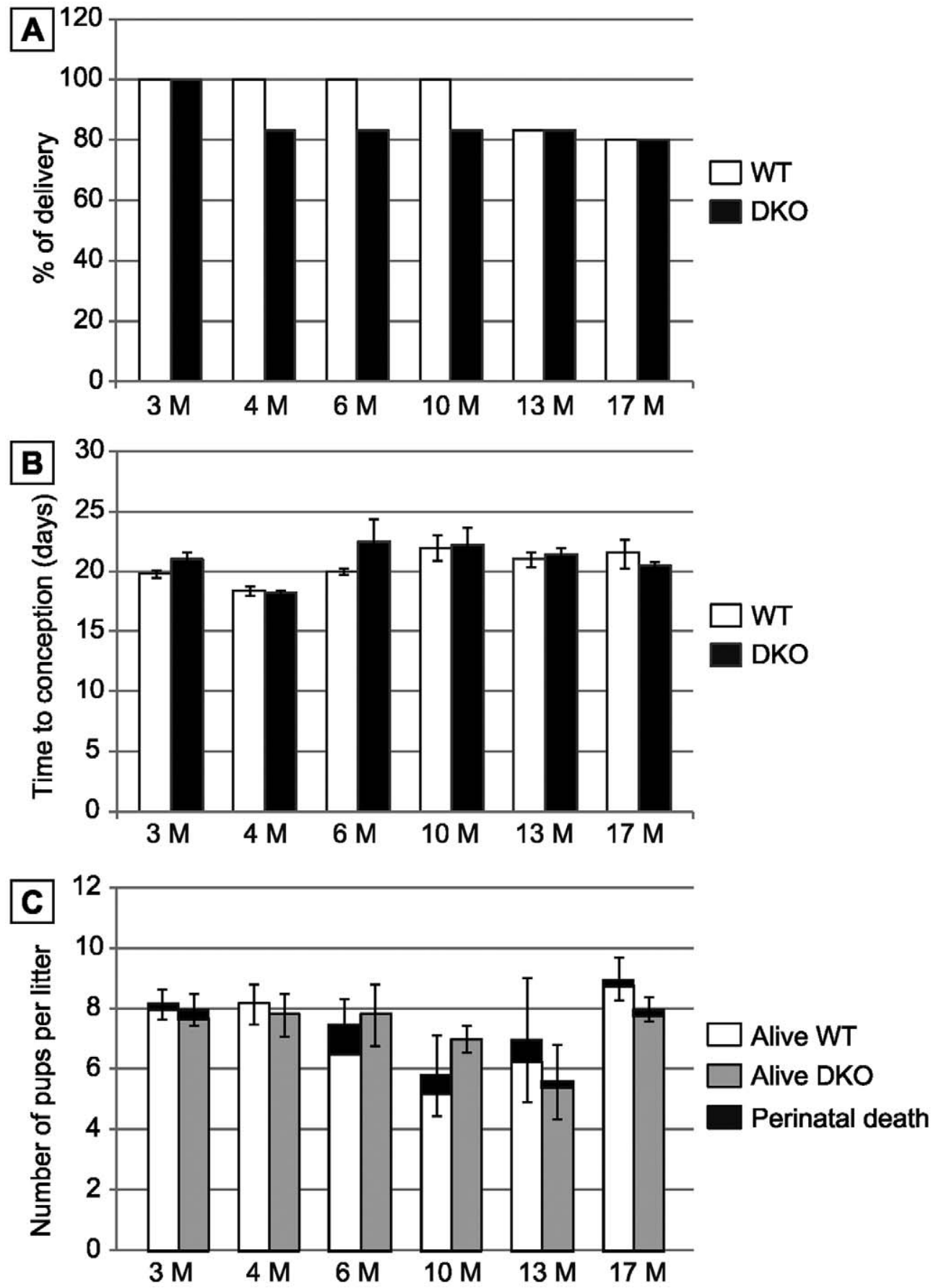

Figure 8. Impact of snGP4 and GPx5 deletions on mouse fertility. A: Histograms plotting the percentage of delivery of several matings between WT or DKO males and WT females (aged 3 months) according to male age given in months. B: Histograms plotting the delay to conception recorded in matings carried out with WT female mice (aged 3 months) and WT or DKO male mice aged 3 to 17 months. (Mean $+/-$ SEM; $n=6)$. C: Histograms plotting the number of pups per litter for WT or DKO males (open bars and grey bars, respectively) according to male age given in months. Black sections indicate the number of dead pups (perinatal mortality). (Mean $+/-\mathrm{SEM} ; n=6$ ). doi:10.1371/journal.pone.0038565.g008 
independent GPx of the 2-cyst-type that uses TRX rather than GSH as an electron donor [39-41]. Finally, together with thioredoxins and peroxiredoxin 3, we have found that glutathione-S-transferases (GST $\pi$ and GST $\mu$ ) are also significantly upregulated both in the caput and cauda epididymidis compartments of the double mutant animals. This agrees with previous reports showing that GSTs are expressed at significant levels in mammalian epididymis [31,42]. Induced expression of multiple forms of GST appears to be an evolutionary response of cells to protect against chemical toxicity and oxidative stress. Therefore, induction of these enzymes in the epididymis of double mutants that lack antioxidant protection is not so surprising. It is interesting to note that different subsets of enzymes are upregulated in the caput and the cauda compartments of double mutant animals compared to WT. The caput overexpresses TXNL1 and GSTs while the cauda overexpresses TXN1, PRDX3 and GSTs. This stronger antioxidant response of the cauda epididymidis of double mutant animals parallels the higher $\mathrm{H}_{2} \mathrm{O}_{2}$-recycling activity we have recorded in that part of the epididymis and indicates the TXN1/PRDX3 couple as the major contributor to this extra $\mathrm{H}_{2} \mathrm{O}_{2}$-recycling activity.

The ability of the epididymis to respond to oxidative stress even when a major luminal player (GPx5) has been invalidated shows the large capacity of this tissue to deal with ROS. It is interesting to note that the antioxidant response of the double mutant cauda epididymidis is sufficient to protect spermatozoa nucleus from oxidative damage in males aged 4 months, whereas it is not so in males aged 8 months. We provided a logical explanation for this observation since it follows the overall loss in cauda epididymidis antioxidant protection on aging as both WT and double mutant animals show an identical decrease in their global cauda $\mathrm{H}_{2} \mathrm{O}_{2^{-}}$ recycling capacity between 4 and 8 months of age. These observations indicate that adaptive responses of the epididymis are inefficient in older animals. Rescue provided by the epididymis antioxidant response in the double mutant context is partly sufficient to correct the deficiency in sperm nuclear disulfide bridging activity and sperm protection against oxidation. Our interpretation of the situation is that the epithelium antioxydant response attempts to counteract a $\mathrm{H}_{2} \mathrm{O}_{2} / \mathrm{LOOH}$-rich luminal environment in order to protect itself. Spermatozoa do benefit from the epithelium antioxidant response because we have shown that cauda sperm of the double KO animals present a lower level of lipid peroxidation than WT spermatozoa. However, because sperm cells in the epididymal lumen cannot mount a stress response they suffer internal ROS-mediated damage such as DNA oxidation essentially because $\mathrm{H}_{2} \mathrm{O}_{2}$ can freely go into any cell compartment.

Thus, the epididymal rescue does not appear to be sufficient to completely protect paternal DNA from oxidative insults, hence the sensitivity to reducing condition that provokes nuclear decompaction, the higher level of DNA fragmentation and susceptibility to DNA oxidation upon aging found in cauda-stored spermatozoa of double mutant animals. Although it is likely that the oxidative insults of the sperm nucleus we recorded in the double $\mathrm{KO}$ animals occurred in the defective epididymal environment, we cannot at this stage rule out the idea that part of these sperm nuclear ROS-mediated damage start during late spermatogenesis when snGPx4 is normally associated with protamines. However, lack of GPx5 expression only affects the antioxydant capacity of the epididymis lumen (26) and snGPx4 was shown to perform its disulfide isomerase job on sperm protamines during their transit through the caput epididymis (24).

Of note is that the epididymis salvage in the double mutant, together with oocyte capacity to repair paternal DNA disorders, are quite sufficient to maintain reproductive success, as double mutant males irrespective of their age were as fertile as WT males when naturally mated with young female mice. This emphasizes the plasticity and the ability of the epididymis to counteract excessive ROS-mediated sperm degradations. Investigations are in progress to determine whether subfertility is encountered in this model when using in vitro fertilization (IVF) which bypass female sperm selection processes [43,44]. Experiments are also conducted to determine whether or not subfertility is observed when using older oocytes which are known to have lost their optimal DNA repair capacity [45].

In conclusion, the epididymis of mice lacking expression of snGPx4 and GPx5 is able to trigger an antioxidant response and to increase disulfide isomerase expression to compensate for the absence of both proteins. Although antioxidant and disulfidebridging activities are increased, they do not completely protect the cauda-stored spermatozoa and, particularly, its nuclear compartment that remains unstable, probably as a result of increased DNA oxidative insults. Our data emphasize that normal sperm nucleus condensation should not be considered as an absolute indicator of full nuclear integrity. Therefore, although MSOME (Motile Sperm Organellar Morphological Examination [46]) offers a powerful method to select morphologically normal spermatozoa for ICSI procedures, it is important to find new techniques that could be used in routine ART to evaluate sperm nuclear integrity prior to IVF and ICSI. This agrees with reports showing that a high sperm DNA Fragmentation Index (DFI) level has a marked effect on the success of implantation in ICSI cycles [47]. It is also in line with the recent suggestions that measurement of sperm DNA damage including oxidation level could be used as a predictor of ART outcome [48,49].

\section{Materials \& Methods}

\section{Animals-Ethics Statement}

The present study was approved by the Regional Ethic Committee for Animal Experimentation (CEMEA-Auvergne; Authorization CE2-04) and adhered to the current legislation on animal experimentation in France. Wild type, snGPx4-/-, and snGPx4;GPx5-/- (DKO) $\mathrm{C} 57 \mathrm{bl} / 6$ male mice either 4 or 8 months old were used throughout the study. Mice were housed under controlled environmental conditions (temperature $22^{\circ} \mathrm{C}, 12$ $\mathrm{h}$ dark period), fed a basal diet (Global-diet, 2016S, Harlan, Gannat, France) ad libitum, and given free access to water. For fertility testing, 10-week old C57bl/6 females were used. All male mice were killed by cervical dislocation.

\section{Genotyping of Mice by PCR}

Genomic DNA was extracted from fingers by ethanol precipitation. Genomic DNA was PCR amplified in a final volume of $25 \mu \mathrm{L}$ in the presence of $2.5 \mathrm{mM} \mathrm{MgCl}_{2}, 400 \mu \mathrm{M}$ dNTPs, $400 \mathrm{nM}$ of each primer and 1.25U GoTaq Flexi DNA polymerase (Promega) by running 2 independent PCR reactions for each gene as described previously [26]. The primers used in this study are described in the Table 2 and in Figure 1A-B.

\section{Fertility Measurements and Spermatozoa Samples}

Wt and sngpx4;gp $x 5^{-/-}$male mice (five each), aged 3 to 17 months, were mated with one C57bl/6 wt synchronized female. At the end of the 7-day reproductive period, males were removed and females were observed to follow eventual pregnancies and deliveries. Time to conceive and number of pups per litter were monitored. For sperm preparations, mice were sacrificed. Epididymides were removed, divided into caput and caudal regions and 
transferred to a small glass dish containing M2 medium (SigmaAldrich, France). To recover the spermatozoa, the caudae epididymides were repeatedly punctured with a needle. After 5 min incubation to allow for sperm dispersal, these preparations were centrifuged at $300 \mathrm{~g}$ for $5 \mathrm{~min}$, and pellets were resuspended in phosphate buffered saline (PBS). Sperm counts were determined using a Malassez hemocytometer.

\section{Cytochemical Tests for Sperm Integrity-Toluidine Blue}

DNA compaction was studied by using the modified protocol of Conrad's group for Toluidine Blue staining [26], where spermatozoa were stained with $1 \% \mathrm{~TB}$ in McIlvain buffer $(200 \mathrm{mM}$ $\mathrm{Na}_{2} \mathrm{HPO}_{4}, 100 \mathrm{mM}$ citric acid, $\mathrm{pH} 3.5$ ) for $17 \mathrm{~min}$ at room temperature. Slides were dehydrated in ethanol and mounted with Cytoseal 60 medium. Three smears per sample were deposited on glass plates and at least 300 spermatozoa per smear were counted. Shorr staining - The sperm morphology was analyzed by Shorr staining [fixation in $70 \%(\mathrm{v} / \mathrm{v})$ aqueous ethanol for $1 \mathrm{~min}$; running water $2 \mathrm{~min}$; Mayer's Hematoxylin (DiaPath) $3 \mathrm{~min}$; running water $3 \mathrm{~min}$; ammoniacal alcohol $10 \mathrm{~s}$; running water $3 \mathrm{~min} ; 70 \%$ ethanol $10 \mathrm{~s}$; 95\% ethanol $10 \mathrm{~s}$; Shorr stain (Merck) 1 min; 95\% ethanol $10 \mathrm{~s} ; 100 \%$ ethanol twice for $10 \mathrm{~s}$; Histo-Clear (National Diagnostics) $10 \mathrm{~s}$; mounting with Richard-Allan Scientific ${ }^{\circledR}$ Cytoseal $^{\mathrm{TM}} 60$ medium (Electron Microscopy Sciences, USA)]. Three smears per sample were deposited on glass plates and at least 300 spermatozoa per smear were counted. Acrosome and nucleus morphology-Acrosome was labeled using lectin PNA Alexa Fluor ${ }^{\circledR}$ 488 conjugate (Invitrogen) and DNA was stained by Hoechst 33342 (Invitrogen). Air-dried smears of spermatozoa were hydrated in PBS and then incubated for $30 \mathrm{~min}$ in PBS, $50 \mu \mathrm{g} /$ mL PNA-Alexa 488 at $37^{\circ} \mathrm{C}$ in the dark. After 2 washes, slides were incubated in Hoechst $33342(1 \mu \mathrm{g} / \mathrm{mL})$ for $5 \mathrm{~min}$ at room temperature, washed 3 times in PBS and mounted with PBS/ glycerol (1:1).

\section{Cytometry}

Spermatozoa of caput or cauda epididymides were diluted with M2 medium to $10^{6}$ sperms $/ \mathrm{ml}$. Flow cytometer evaluation was performed using a Calibur cytometer (Becton Dickinson, Le Pont de Claix, France). For each analysis, 10,000 events were counted using specific probes as described thereafter. Argon laser excitation at $488 \mathrm{~nm}$ was coupled with emission measurements at 530/30 (red) and 585/42 (green) band pass, respectively. Non-specific sperm events were gated out. The data were analysed with logiciel CellQuest Pro software (Becton Dickinson, Le Pont de Claix, France). Percentages of living and dead cells were assessed using propidium iodide $(\mathrm{PI})(0.01 \mathrm{mg} / \mathrm{ml}$, Sigma). PI was incubated with sperm cells for $8 \mathrm{~min}$ at $37^{\circ} \mathrm{C}$, then cells were analysed by cytometry on FL3 channel $(>650 \mathrm{~nm})$. Sperm total thiol contents were determined using monobromobimane as a probe $(\mathrm{mBrB}$ [Thiolyte], Calbiochem, VWR, Fontenay sous Bois, France). A $50 \mathrm{mM}$ solution stock was diluted in $100 \%$ acetonitrile. Sperm cells were stained with $1 \mathrm{mM} \mathrm{mBrB}$ for $30 \mathrm{~min}$ at $25^{\circ} \mathrm{C}$ then washed twice with PBS. Free thiols were measured by fluorescence on FLl channel (515-545 nm). To evaluate sperm chromatin condensation, sperm cells were stained with $0.25 \mathrm{mg} / \mathrm{ml}$ chromomycin A3 (CMA3, Sigma, France) for $20 \mathrm{~min}$ at $25^{\circ} \mathrm{C}$. Sperm nuclei decondensation level was measured by cytometry on FL2 channel (564-606 nm).

\section{Peroxidase Activity Assay}

Analyses of peroxidase activity were performed as previously described [38] using hydrogen peroxide $(200 \mu \mathrm{M})$ as a substrate and glutathione $(3 \mathrm{mM})$ /glutathione reductase $(1.4 \mathrm{U})$. NADPH oxidation was monitored at $340 \mathrm{~nm}$.

\section{Lipid Peroxidation Assay}

Lipid peroxidation (LPO) in the tissues was measured by thiobarbituric acid reacting substance (TBARS) and was expressed in terms of malondialdehyde (MDA) content. Sample aliquots were incubated with $10 \%$ trichloroacetic acid and $0.67 \%$ thiobarbituric acid. The mixture was heated in a boiling water bath for $30 \mathrm{~min}$, an equal volume of n-butanol was added, and the final mixture was centrifuged; the organic phase was collected for fluorescence measurements. Samples assayed for MDA contained $1 \mathrm{mM}$ butylated hydroxytoluene (BHT) in order to prevent artefactual LPO during the boiling step. The absorbance of samples was determined at $532 \mathrm{~nm}$. Results were expressed as $\mu \mathrm{mol} \mathrm{MDA} \mathrm{g}{ }^{-1}$ protein.

\section{Sperm DNA Fragmentation Assay}

Assessment of sperm DNA fragmentation was carried out using the staining protocol of the Halomax kit (Chromacell, Spain), a modified Sperm Chromatin Dispersion Assay [28]. Four smears per sample were deposited on glass plates and at least 500 spermatozoa per smear were counted.

\section{Evaluation of DNA Peroxidative Damages}

8-hydroxy-2'-deoxyguanosine detection (8-oxodG) was carried out on spermatozoa from cauda epididymidis. Spermatozoa were resuspended in a decondensing buffer consisting of $2 \mathrm{mM}$ DTT and $0.5 \%$ Triton X-100 in PBS $1 \mathrm{X}$ and incubated for one hour at room temperature. After centrifugation at $300 \mathrm{~g}$ for $5 \mathrm{~min}$ at room temperature, spermatozoa were washed in PBS and smeared on a glass plate (30.000 cells/plate). WT and DKO spermatozoa were compared for their reactivity towards the 8-oxodG monoclonal antibody (15A3, Novus biological, Interchim, France). As a positive control of oxidative damage of sperm DNA, a WT spermatozoa aliquot was treated for 2 hours at room temperature by $0.02 \% \mathrm{H}_{2} \mathrm{O}_{2}$. Incubations with the primary antibody (dilution $1 / 500$ ) were conducted overnight at $4^{\circ} \mathrm{C}$. Then, after two washes in PBS $1 \mathrm{X}$, Triton X-100 0.1\%, the secondary antibody was applied for 1 hour at room temperature (dilution 1/500, antimouse IgG polyclonal coupled HRP, P.A.R.I.S Anticorps, France). Signal detection was obtained by the use of the Vector Nova Red substrate kit for peroxidase (Vector Laboratories, AbCys, Paris, France). Two smears per sample were deposited on glass plates and at least 300 spermatozoa per smear were counted.

\section{Microscopy}

Observations and counts of Shorr staining, Toluidine blue staining and DNA fragmentation assay were made in transmitted light with the Axioskop (Carl Zeiss, Germany), using magnification of x400. 8-oxodG-positive spermatozoa were counted by Axioplan2 imaging (Carl Zeiss, Germany) in transmitted light (magnification: x630). Observations of fluorescent probes were made by Axioplan2 imaging (Carl Zeiss, Germany) at excitation and emission wavelengths: Alexa 488, BP 475/40 and BP 530/50; Hoechst 33342, BP 365/12 and LP 397, respectively (magnification: $\mathrm{x} 1000)$.

\section{Quantitative Reverse Transcriptase Polymerase Chain Reaction}

Total RNAs were isolated with the NucleoSpin ${ }^{\circledR}$ RNA II kit (Macherey-Nagel, France). Total RNAs were reverse transcribed by M-MLV Reverse Transcriptase (Promega Corp., France) 
Table 2. Primer sequences used for genotyping of transgenic animals and real time PCR amplifications of selected thiol peroxidases and antioxidant-related genes.

\begin{tabular}{|c|c|c|c|c|}
\hline Target & GenBank & $5^{\prime}-3^{\prime}$ primers sequences & Size (bp) & Melting $\left({ }^{\circ} \mathrm{C}\right)$ \\
\hline \multicolumn{5}{|l|}{ Genotyping } \\
\hline sngpx4 & NC_000076.5 & $\begin{array}{l}\text { P1/F - TCGGCGGCGCCTTGGCTACCGGCTC } \\
\text { P2/R - GGATCCGCCGCGCTGTCTGCAGCGTCCCC } \\
\text { P3/R - TGAAGAAGTCGTGCTGCTTCATGTGG }\end{array}$ & $\begin{array}{l}119 \\
342\end{array}$ & 60 \\
\hline$g p \times 5$ & NC_000079.5 & $\begin{array}{l}\text { P4/F - GTGTCTGAGAATCTAGTCCTAGC } \\
\text { P5/R - GTGACAGTIITCTCAGGGGTTGG } \\
\text { P6/R - CTGCCTTGTGAAGGTTGACAGG }\end{array}$ & $\begin{array}{l}263 \\
1498 / 278\end{array}$ & 60 \\
\hline \multicolumn{5}{|l|}{ q-PCR } \\
\hline cyclophilin B & NM_011149.2 & $\begin{array}{l}\text { F - GGAGATGGCACAGGAGGAA } \\
\text { R - GCCCGTAGTGCTTCAGCTT }\end{array}$ & 76 & 57 à 62 \\
\hline$g p \times 1$ & NM_008160.5 & $\begin{array}{l}\mathrm{F} \text { - GTCCACCGTGTATGCCTTCT } \\
\mathrm{R} \text { - CTCCTGGTGTCCGAACTGAT }\end{array}$ & 217 & 62 \\
\hline$g p \times 3$ & NM_008161.2 & $\begin{array}{l}\text { F - TCGGAGATACTCCCCAGTC } \\
\text { R - AGTTCCAGCGGATGTCATGG }\end{array}$ & 211 & 58 \\
\hline$g p \times 4$ & NM_008162.2 & $\begin{array}{l}\text { F - AGTACAGGGGTTTCGTGTGC } \\
\text { R - CGGCAGGTCCTTCTCTATCA }\end{array}$ & 410 & 62 \\
\hline Catalase & NM_009804.2 & $\begin{array}{l}\text { F - GCAGATACCTGTGAACTGTC } \\
\text { R - GTAGAATGTCCGCACCTGAG }\end{array}$ & 229 & 62 \\
\hline $\operatorname{sod} 3$ & NM_011435.3 & $\begin{array}{l}\text { F - GCTCTCAGAGAACCCCTCT } \\
\text { R - GTGCTATGGGGACAGGAAGA }\end{array}$ & 170 & 58 \\
\hline $\operatorname{prd} \times 1$ & NM_011034.4 & $\begin{array}{l}\text { F - CAACTGCCAAGTGATTGGCG } \\
\text { R - TGAGCAATGGTGCGCTTGGG }\end{array}$ & 135 & 59 \\
\hline $\operatorname{prd} \times 2$ & NM_011563.5 & $\begin{array}{l}\mathrm{F} \text { - TGACTTCACGGCCACAGCGG } \\
\mathrm{R} \text { - CGGAAGTCCTCAGCATGGTC }\end{array}$ & 159 & 61 \\
\hline $\operatorname{prdx3}$ & NM_007452.2 & $\begin{array}{l}\text { F - CAGACATACTGTGGTCTGCC } \\
\text { R - AAGTCGTCGAGACTCAGCTC }\end{array}$ & 151 & 59 \\
\hline $\operatorname{prdx} 4$ & NM_016764.4 & $\begin{array}{l}\text { F - CAGGACATACTCTTAGAGGCC } \\
\text { R - TCACTACCAGGTITCCAGCC }\end{array}$ & 178 & 62 \\
\hline prdx5 & NM_012021.2 & $\begin{array}{l}\text { F - CGTGCATCGACGTGCTTGGC } \\
\text { R - ACCTCCACTGAGGGAATGGC }\end{array}$ & 137 & 60 \\
\hline prdx6 & NM_007453.3 & $\begin{array}{l}\mathrm{F} \text { - CACAGAACTTGGCAGAGCTG } \\
\mathrm{R} \text { - TCGACTGGATCCAACATGCC }\end{array}$ & 219 & 59 \\
\hline txn1 & NM_011660.3 & $\begin{array}{l}\text { F - TGGTGAAGCTGATCGAGAGC } \\
\text { R - GGAATACTTGTCACAGAGGG }\end{array}$ & 149 & 59 \\
\hline$t \times n 2$ & NM_019913.5 & $\begin{array}{l}\text { F - GGTGGTCATGGCCAAAGTGG } \\
\text { R - CTTCTAGCTGGTCCTCGTCC }\end{array}$ & 146 & 61 \\
\hline txnl1 & NM_016792.4 & $\begin{array}{l}\text { F - ACTGTGGCATTCAATCAGCC } \\
\text { R - AGTTGGCTCACTCCTTTCCG }\end{array}$ & 144 & 57 \\
\hline txndc2 (sptrx1) & NM_001146002.1 & $\begin{array}{l}\text { F - GGAGCTCCTGAAGAGTCGG } \\
\text { R - GGCCTTCTCTTTGGACTGGG }\end{array}$ & 150 & 62 \\
\hline txndc3 (sptrx2) & NM_181591.3 & $\begin{array}{l}\text { F - CCCTGAAGAGGTAGTGAGGG } \\
\text { R - GGTGCAAACCTAACGTGAGGC }\end{array}$ & 207 & 59 \\
\hline txndc8 (sptrx3) & NM_026132.2 & $\begin{array}{l}\text { F - GTTTGCTCAGGTGGATGTGG } \\
\mathrm{R}-\mathrm{CTTCGGTCCACTTCTGAGGC}\end{array}$ & 154 & 62 \\
\hline gst $\mu$ & $\begin{array}{l}\text { NM_010358.5 } \\
\text { NM_008183.3 }\end{array}$ & $\begin{array}{l}\text { F - GAAGTTCAAGCTGGGCCTGG } \\
\text { R - GCATGATGAGCTGCATGCGG }\end{array}$ & 194 & 59 \\
\hline gst $\pi$ & $\begin{array}{l}\text { NM_013541.1 } \\
\text { NM_181796.2 }\end{array}$ & $\begin{array}{l}\text { F - AGCTTTCATCGTGGGTGACC } \\
\text { R - GGGACGGTTCACATGTTCCG }\end{array}$ & 187 & 59 \\
\hline pdia3 (erp57) & NM_007952.2 & $\begin{array}{l}\text { F - GGACATTGCAAGAGGCTTGCCC } \\
\text { R - TAGGCCCATCATAAGCACCCGC }\end{array}$ & 184 & 62 \\
\hline pdia4 (erp72) & NM_009787.2 & $\begin{array}{l}\mathrm{F} \text { - TGATGGCTCCAGGACCCAGG } \\
\mathrm{R} \text { - TTGCTGAGCTCCTTGGCAGC }\end{array}$ & 222 & 61 \\
\hline pdia5 & NM_028295.1 & $\begin{array}{l}\mathrm{F} \text { - TITCCAGAAGGCTGCCACCC } \\
\mathrm{R} \text { - CTCCACGATGTCCTCGGCC }\end{array}$ & 190 & 62 \\
\hline pdia6 (txndc7) & NM_027959.3 & $\begin{array}{l}\mathrm{F} \text { - TGGAAGAAAGCAGCAACGGC } \\
\mathrm{R} \text { - CATCTACAATGGCTTCTCCC }\end{array}$ & 184 & 57 \\
\hline pdia10 (txndc4/erp44) & NM_029572.2 & $\begin{array}{l}\text { F - CAGATTGCCCTGTCATAGCC } \\
\text { R - TGTCAGTCGGGTCAGGTCCG }\end{array}$ & 159 & 57 \\
\hline
\end{tabular}


Table 2. Cont.

\begin{tabular}{|c|c|c|c|c|}
\hline Target & GenBank & $5^{\prime}-3^{\prime}$ primers sequences & Size (bp) & Melting $\left({ }^{\circ} \mathrm{C}\right)$ \\
\hline pdia11 (txndc1) & NM_028339.1 & $\begin{array}{l}\text { F - GCTTGTCAGAATCTTCAGCC } \\
\text { R - CACATAGCGCCTAAATTCACC }\end{array}$ & 174 & 60 \\
\hline
\end{tabular}

according to the manufacturer's instruction. Quantitative real time PCR assays were performed using a RealPlex thermocycler (Eppendorf). Two $\mu \mathrm{L}$ of diluted cDNA template (1/20 caput epididymidis; $1 / 5$ cauda epididymidis) were amplified using MESA GREEN qPCR MasterMix Plus (Eurogentec, France) according to the manufacturer's instructions. Primer sequences are given in Table 2. A standard curve of amplification efficiency for each set of primers was generated with a serial dilution of plasmids containing DNA of targeted genes. Melting curve analysis was carried out to confirm the specificity of primers. For quantification of transcripts, the relative method was used to calculate mRNA relative level to Cyclophilin $B$ standard.

\section{Statistical Analysis}

Kruskal-Wallis and Mann-Whitney nonparametric tests were performed with GraphPad Prism 5.02 software to determine the

\section{References}

1. Kodama H, Yamaguchi R, Fukuda J, Kasai H, Tanaka T (1997) Increased oxidative deoxyribonucleic acid damage in the spermatozoa of infertile male patients. Fertil Steril 68: 519-524.

2. Spano M, Bonde JP, Hjollund HI, Kolstad HA, Cordelli E, et al. (2000) Sperm chromatin damage impairs human fertility. The Danish First Pregnancy Planner Study Team. Fertil Steril 73: 43-50.

3. Zini A, Bielecki R, Phang D, Zenzes MT (2001) Correlations between two markers of sperm DNA integrity, DNA denaturation and DNA fragmentation, in fertile and infertile men. Fertil Steril 75: 674-677.

4. Tesarik J, Greco E, Mendoza C (2004) Late, but not early, paternal effect on human embryo development is related to sperm DNA fragmentation. Human Reprod 19: 611-615.

5. Lewis SEM, Aitken RJ (2005) DNA damage to spermatozoa has impacts on fertilization and pregnancy. Cell Tissue Res 322: 33-41.

6. O'Brien J, Zini A (2005) Sperm DNA integrity and male infertility. Urology 65: $16-22$.

7. Zini A, Libman J (2006) Sperm DNA damage: clinical significance in the era of assisted reproduction. Curr Opin Urol 16(6): 428-434.

8. Tesarik J, Mendoza-Tesarik R, Mendoza C (2006) Sperm nuclear DNA damage: update on the mechanism, diagnosis and treatment. Reprod Biomed Online 12: 715-721.

9. Cocuzza M, Sikka SC, Athayde KS, Agarwal A (2007) Clinical relevance of oxidative stress and sperm chromatin damage in male infertility: an evidence based analysis. Int Braz J Urol 33: 603-621.

10. Marchesi DE, Feng HL (2007) Current assessment of sperm DNA integrity. (2007) Arch Androl 53(5): 239-247.

11. Aitken RJ, De luliis GN, McLachlan RI (2008) Biological and clinical significance of DNA damage in the male germ line. Int J Androl 32: 46-56.

12. Aoki VW, Moskovtsev SI, Willis J, Liu L, Mulen JB., et al. (2005) DNA integrity is compromised in protamine-deficient human sperm. J Androl 26: 741-748.

13. Sakkas D, Alvarez JG (2009) Sperm DNA fragmentation: mechanisms of origin, impact on reproductive outcome, and analysis. Fertil Steril 93: 1027-1036.

14. Ward WS, Coffey DS (1991) DNA packaging and organization in mammalian spermatozoa: comparison with somatic cells. Biol Reprod 44: 569-574.

15. Miller D, Brinkworth M, Iles D (2010) Paternal DNA packaging in spermatozoa: more than the sum of its parts? DNA, histones, protamines and epigenetics. Reproduction 139: 287-301.

16. Calvin HI, Bedford JM (1971) Formation of disulphide bonds in the nucleus and accessory structures of mammalian spermatozoa during maturation in the epididymis. J Reprod Fertil 13: 65-75.

17. Bedford JM, Calvin HI (1974) Changes in -S-S- linked structures of the sperm tail during epididymal maturation, with comparative observations in submammalian species. F Exp Zool 187: 137-156. significance of differences between samples. $P$ values of $\leq 0.05$ were regarded as significant.

\section{Acknowledgments}

We are indebted to Dr. Felicity Vear (Institut Natioanal de la Recherche Agronomique, Clermont-Ferrand, France) and Dr. Peter Ofner (Institut für Funktionelle Genomik Universität Regensburg, Germany) for English grammar and syntax corrections.

\section{Author Contributions}

Conceived and designed the experiments: JRD AK FS RG PV MC. Performed the experiments: AN MP CDS EG NK AK. Analyzed the data: JRD AK LJ HPR MC. Contributed reagents/materials/analysis tools: MC. Wrote the paper: JRD AN AK.

18. Shalgi R, Seligman J, Kosover NS (1989) Dynamic of the thiol status of rat spermatozoa during maturation: analysis with the fluorescent lebelling agent monobromobimane. Biol Reprod 40: 1037-1045.

19. Seligman J, Kosower NS, Weissenberg R, Shalgi R (1994) Thiol-disulfide status of human sperm proteins. J. Reprod. Fertil 101: 435-454.

20. Balhorn R, Corzett M, Mazrimas J, Watkins B (2001) Identification of bull protamine disulfides. Biochemistry 30: 175-181.

21. Yeung CH, Barfield JP, Cooper TG (2006) Physiological volume regulation by spermatozoa. Mol cell Endocr 250: 98-105.

22. Huang HF, Nieschlag E (1984) Alteration of free sulphydryl content of rat sperm heads by suppression of intratesticular testosterone. J Reprod Fertil 70: 31-38.

23. Golan R, Cooper TG, Oschry Y, Oberpenning F, Schulze H, et al. (1996) Changes in chromatin condensation of human spermatozoa during epididymal transit as determined by flow cytometry. Hum Reprod 11: 1457-1462.

24. Conrad M, Moreno SG, Sinowatz F, Ursini F, Kölle S, et al. (2005) The nuclear form of phospholipid hydroperoxide glutathione peroxidase is a protein thiol peroxidase contributing to sperm chromatin stability. Mol Cell Biol 25: 7637 7644.

25. Pfeifer H, Conrad M, Roethlein D, Kyriakopoulos A, Brielmeier M, et al. (2001) Identification of a specific sperm nuclei selenoenzyme necessary for protamine thiol cross-linking during sperm maturation. FASEB J 15: 1236-1238.

26. Chabory E, Damon C, Lenoir A, Kauzelmann G, Kern H, et al. (2009) Epididymis seleno-independent glutathione peroxidase 5 maintains sperm DNA integrity in mice. J Clin Invest 119: 2074-2085.

27. Noblanc A, Kocer A, Chabory E, Vernet P, Saez F, et al. (2011) Glutathione peroxidases (GPx) at work on epididymal spermatozoa: an example of the dual effect of reactive oxygen species on mammalian male fertilizing ability. J Androl 32(6): $641-650$.

28. Fernandez JL, Muriel M, Rivero MT, Goyanes V, Vazquez R, et al. (2003) The sperm chromatin dispersion test: a simple method for the determination of sperm DNA fragmentation. J Androl 24: 59-66.

29. Puglisi R, Maccari I, Pipolo S, Conrad M, Mangia F, et al. (2011) The nuclear form of glutathione peoxidase 4 is associated with sperm nuclear matrix and is required for proper paternal chromatin decondensation at fertilization. J Cell Physiol, [Epub ahead of print, doi:10.1002/jcp.22857]

30. Anelli T, Alessio M, Mezghrani A, Simmen T, Talamo F,et al. (2002) Erp44, a novel endoplasmic reticulum folding assistant of the thioredoxin family. EMBOJ 15(21): 835-844.

31. Johnston DS, Jelinsky SA, Bang HJ, DiCandeloro P, Wilson E, et al. (2005) The mouse epididymal transcriptome: transcriptional profiling of segmental gene expression in the epididymis. Biol Reprod 73: 404-413.

32. Quan X, Lim S, Jung G (2011). Reactive oxygen species downregulate catalase expression via methylation of a CpG Island in the Oct-1 promoter. FEBS Let 585: 3436-3441. 
33. Arner ES, Holmgren A (2000) Physiological functions of thioredoxin and thioredoxin reductase. Eur J Biochem 267: 6102-6109.

34. Wood ZA, Schroder E, Robin-Harris J, Poole LB (2003) Structure, mechanism and regulation of peroxiredoxins. Trends Biochem 28: 32-40.

35. Peskin AV, Low FM, Paton LN, Maghzal GJ, Hampton MB (2007) The high reactivity of peroxiredoxin 2 with $\mathrm{H}(2) \mathrm{O}(2)$ is not reflected in its reaction with other oxidants and thiol reagents. J Biol Chem 282: 11885-11892.

36. Berggren MI, Husbeck B, Samulitis B, Baker AF, Gallegos A, et al. (2001) Thioredoxin peroxidase-1 (peroxiredoxin-1) is increased in thioredoxin-1 transfected cells and results in enhanced protection against apoptosis caused by hydrogen peroxide but not by other agents including dexamethasone, etoposide, and doxorubicin. Arch Biochem Biophys 392: 103-109.

37. Chevallet M, Wagner E, Luche S, van Dorsselaer A, Leize-Wagner E, et al. (2003) Regeneration of peroxiredoxins during recovery after oxidative stress: only some overoxidized peroxiredoxins can be reduced during recovery after oxidative stress. J Biol Chem 278: 37146-37153.

38. Lee W, Wells T, Kantorow M (2007) Localization and $\mathrm{H}_{2} \mathrm{O}_{2}$-specific induction of PRDX3 in the eye lens. Mol Vis 13: 1469-1474.

39. Herbette S, Lenne C, Leblanc N, Julien JL, Drevet JR, et al. (2002) Two GPXlike proteins from Lycopersicon esculentum and Helianthus annuus are antioxidant enzymes with phospholipid hydroperoxide glutathione peroxidase and thioredoxin peroxidase activities. Eur J Biochem 269: 2414-2420.

40. Herbette S, Roeckel-Drevet P, Drevet JR (2007) Seleno-independent glutathione peroxidases. More than simple antioxidant scavengers. FEBS J 274: 2163-2180.

41. Flohe'L, Toppo S, Cozza G, Ursini F 2(011) A Comparison of Thiol Peroxidase Mechanisms. Antioxidants \& Redox Signaling 15(3): 763-780.
42. Montiel EE, Huidobro CC, Castellon EA (2003) Glutathione-related enzymes in cell cultures from different regions of human epididymis. Arch Androl 49: 95105.

43. Zini A, Boman JM, Belzile E, Ciampi A (2008) Sperm DNA damage is associated with an increased risk of pregnancy loss after IVF and ICSI: systematic review and meta-analysis. Hum Reprod 23(12): 2663-2668.

44. Satake N, Elliott RM, Watson PE, Holt W (2006) Sperm selection and competition in pigs may be mediated by the differential motility activation and suppression of sperm subpopulations within the oviduct. J Exp Biol 209: 15601572 .

45. Meseguer M, Santiso R, Garrido N, Garcia-Herreo S, Remohi J, et al. (2011) Effect of sperm DNA fragmentation on pregnancy outcome depends on oocyte quality. Fertil Steril 95(1): 124-128.

46. Bartoov B, Berkovitz A, Eltes F, Kogosowski A, Yagoda A, et al. (2003) Pregnancy rates are higher with intracytoplasmic morphologically selected sperm injection than with conventional intracytoplasmic injection. Fertil Steril 80(6): 1413-1419.

47. Speyer BE, Pizzey AR, Ranieri M, Joshi R, Delhanty JD, et al. (2010) Fall in implantation rates following ICSI with sperm with high DNA fragmentation. Hum Reprod 25(7): 1609-1618.

48. Simon L, Brunborg G, Stevenson M, Lutton D, McManus J, et al. (2010) Clinical significance of sperm DNA damage in assisted reproduction outcome. Hum Reprod 25(7): 1594-1608.

49. Simon L, Castillo J, Oliva R, Lewis SE (2011) Relationships between human sperm protamines, DNA damage and assisted reproduction outcome. Reprod Biomed Online 23(6): 724-734. 